\title{
Separation of Peptide Groups with Definite Characteristics from Enzymatic Protein Hydrolysate
}

\author{
Shuji Adachi, Yukitaka Kimura, Koji MuraKami, \\ Ryuichi MATSUNO and Hidehiko Yokogoshi* \\ Department of Food Science and Technology, Faculty of Agriculture, \\ Kyoto University, Sakyo-ku, Kyoto 606, Japan \\ * School of Food and Nutritional Sciences, University of Schizuoka, \\ Yada, Shizuoka 422, Japan \\ Received July 18, 1990
}

\begin{abstract}
For producing peptides with definite characteristics from a casein hydrolysate treated consecutively with thermolysin and papain, the hydrolysate was separated through two chromatographic steps into four peptide groups with high or low contents of aromatic amino acids (AAA) and branched chain amino acids (BCAA). The hydrolysate was first separated into AAA-poor and -rich peptide groups (one-half and 3 to 4 times as high as the AAA content of the hydrolysate) by both a conventional batch chromatography with Sephadex G-15 and a continuous one, with the same resin, of a simulated moving-bed type. The AAA-poor peptide group was further separated into a BCAArich (about 1.5-fold) peptide group and another one with an increased content of hydrophilic amino acids by batch chromatography with Toyopearl HW-40S.
\end{abstract}

Peptides with characteristic amino acid compositions are desirable in nutritional and food sciences. The content of branched chain amino acids (BCAA) in amino acid mixtures or peptides has been related to improvement of a liver disease. ${ }^{1)}$ Peptides are superior to free amino acids, of which they are constructed, in increasing the assimilation rate at the brush border membrane and in reducing osmotic pressure. ${ }^{2)}$ On the other hand, it is also known that the hydrophobic amino acids are bitter ${ }^{3)}$ and that reduction of the content of aromatic amino acids (AAA) in a protein hydrolysate improves its taste. ${ }^{4)}$ In this context, preparation of peptides with definite characteristics may be useful and promising in producing physiologically functional food.

There are two ways to obtain such peptides. One is an enzymatic or chemical synthesis of peptides from their constituent amino acids. We have synthesized a variety of peptides enzymatically. ${ }^{5,6)}$ Another, which is the subject of this report, is a separation of characteristic peptide groups from an enzymatic protein hydrolysate. The latter may be economically superior to the former when the peptides are used as foodstuffs.

The aim of this work is to prepare four groups of peptides with definite characteristics from an enzymatic casein hydrolysate through two separation steps. Casein is used as a protein to be hydrolyzed because it is edible, its composition is known, and it is usually used as a substrate for the digestion test by proteinases. It may also be easily hydrolyzed due to its low content of carbohydrate. In the first separation step, the hydrolysate is separated into AAA-poor and -rich peptide groups, designated peptide groups I and II, respectively. The AAA-poor peptide group I is further separated into BCAA-rich and -poor peptide groups $\mathrm{Ia}$ and $\mathrm{Ib}$ in the second separation step. The separation system to be established is summarized as follows:

protein hydrolysate-

$\longrightarrow$ AAA-poor peptide group I-
$\longrightarrow$ AAA-rich peptide group II
$\longrightarrow$ BCAA-rich peptide group Ia
$\longrightarrow$ BCAA-poor and hydrophilic
peptide group Ib


Peptide group I, with reduced AAA content, may be used as a debittered peptide mixture in food. Group Ia, the BCAA content of which is enhanced, may be useful as a physiologically functional food or for medical supplies.

To achieve the separations mentioned above, we aimed to use the weakly hydrophobic interaction between AAA or BCAA and a gel chromatographic resin. Most resins have more or less of such an interaction. Removal of free AAA and AAA-rich peptides from protein hydrolysates with Sephadex G-15 has already been demonstrated.7) In this study, the separation of AAA-rich and -poor peptide groups is done continuously using a chromatography of a simulated moving-bed type with the resin as well as a conventional batch one. The further separation of the AAA-poor peptide group I into the BCAA-rich and -poor peptide groups is also shown with another gel chromatographic resin, Toyopearl HW-40S, which is used in a conventional batch chromatography.

\section{Materials and Methods}

Materials. Casein was purchased from Wako Pure Chemicals. Thermolysin and papain were obtained from Daiwa Kasei Kogyo and Wako Pure Chemicals, respectively. Other proteinases were also commercially available ones. The enzymes and casein were used without further purification. The gel chromatographic resins, Sephadex G-15, Bio-Gel P-2, and Toyopearl HW-40S, were purchased from Pharmacia, Bio-Rad, and Tosoh, respectively. Other chemicals were of analytical grade.

Enzymatic hydrolysis of casein. As preliminary experiments, single or dual (consecutive) hydrolyses of casein were done, using some proteinases at their optimum pHs with appropriate buffer solutions. The proteinases tested were $\alpha$-chymotrypsin (Sigma), thermolysin, papain, pepsin (Sigma), trypsin (Wako Pure Chemicals), and a neutral protease (Seikagaku Kogyo). The reaction progresses were followed by the ninhydrin method ${ }^{8)}$ for $5 \%(\mathrm{w} / \mathrm{v})$ trichloroacetic acid (TCA)-soluble portions, leucine being used as a standard. Among the hydrolyses examined, the consecutive hydrolysis by thermolysin and papain gave the highest conversion. Therefore, this hydrolysis was adopted hereafter.

Casein $(10 \mathrm{~g})$ was suspended in $200 \mathrm{ml}$ of distilled water, and the $\mathrm{pH}$ was adjusted to 7.5 by $1.0 \mathrm{M}$ sodium carbonate. Thermolysin $(0.10 \mathrm{~g})$ was then added to the suspension, and the first step of hydrolysis was done at $37^{\circ} \mathrm{C}$. During the reaction, the $\mathrm{pH}$ was maintained at $7.5 \pm 0.1$ by automatically feeding $1.0 \mathrm{M}$ sodium carbonate. At appropriate intervals, a portion of the reaction mixture was pipetted out and poured into TCA solution, the final concentration of which was $5 \%(\mathrm{w} / \mathrm{v})$. After centrifugation, the concentration of ninhydrin-positive substances in the supernatant was measured. When $300 \mathrm{~min}$ had elapsed, the reaction vessel was immersed in hot water $\left(95-100^{\circ} \mathrm{C}\right)$ for $15 \mathrm{~min}$ to stop the first thermolysin-catalyzed hydrolysis.

The reaction mixture was then cooled to $37^{\circ} \mathrm{C}$, and its $\mathrm{pH}$ was adjusted to 6.5 by $1.0 \mathrm{M}$ hydrochloric acid. Mercaptoethanol $(0.4 \mathrm{ml})$ was also added. The second hydrolysis was started by adding $0.10 \mathrm{~g}$ of papain. The hydrolysis proceeded at $\mathrm{pH} 6.5 \pm 0.1$ for $180 \mathrm{~min}$.

Estimation of hydrophobicity of resins. Using the method of Motozato et al., ${ }^{9}$ ) we estimated the hydrophobicity of each resin from the elution volumes of $n$-alcohols in its bed. The resin gels to be examined were packed into a glass column $0.9 \mathrm{~cm}$ in inner diameter. The bed height was about $28 \mathrm{~cm}$; it was measured exactly for each experiment. One-tenth $\mathrm{ml}$ of $5 \%(\mathrm{v} / \mathrm{v}) n$-alcohol was put on the bed and then eluted with distilled water at a flow rate of $0.18 \mathrm{ml} / \mathrm{min}$. The elution profiles were monitored with a differential refractometer (Showa Denko, SE-11), and recorded. The operation was done at room temperature. The $n$-alcohols used were methanol, ethanol, propanol, and butanol.

Conventional batch chromatography. To obtain the AAA-poor peptide group I and the AAA-rich peptide group II from the casein hydrolysate, conventional batch chromatography with Sephadex G-15 was done at room temperature. The eluent used was distilled water, although Yamashita et $a l{ }^{7}{ }^{7}$ had used $0.5 \mathrm{M}$ acetic acid or $10 \%$ ethanol as the eluent for the same resin. The Sephadex G-15 gels were packed into a cylindrical glass column. The bed size was $5.1 \mathrm{~cm}$ i.d. $\times 48.8 \mathrm{~cm}$. Fifteen $\mathrm{ml}$ of the casein hydrolysate was put onto the top of the bed, and then eluted at the flow rate of $3.47 \mathrm{ml} / \mathrm{min}$. The effluent was collected at the outlet of the bed every $3 \mathrm{~min}$. The absorbances at 220 and $280 \mathrm{~nm}$ and the concentration of ninhydrin-positive substances were measured for each fraction. The absorbance at $280 \mathrm{~nm}$ may reflect the amount of AAA. On the other hand, the absorbance at $220 \mathrm{~nm}$ may be an indication of the amount of peptide bonds, although AAA absorbs light of this wavelength.

To prepare the BCAA-rich and -poor peptide groups from peptide group I, peptide group I prepared by the chromatography with Sephadex G-15 was again put through conventional batch chromatography with Toyopearl HW-40S at room temperature, after it was lyophilized and dissolved in water to give the concentration of $5.0 \%$ $(w / v)$. The bed of the resin was $2.1 \mathrm{~cm}$ in inner diameter and $45.0 \mathrm{~cm}$ in height. Two and a half $\mathrm{ml}$ of the peptide group I solution was put on and eluted with distilled water 
at $0.40 \mathrm{ml} / \mathrm{min}$. The effluent was fractionated every $8 \mathrm{~min}$, and then the absorbances at 220 and $280 \mathrm{~nm}$ and the concentration of ninhydrin-positive substances were measured for each fraction. Analysis of amino acid composition was also done for some fractions.

Continuous chromatography of a simulated moving-bed type. As shown later, the peptide groups I and II had fairly different retention times in the batch chromatography with Sephadex G-15. The difference in the retention time between them was thought to be enough to make continuous separation possible, so it was done at room temperature with chromatography of a simulated movingbed type, which had been described previously. ${ }^{10-12}$ Sephadex G-15 gels were packed into four columns with the same dimensions. The inner diameter of each column was $1.27 \mathrm{~cm}$. The columns were connected to make a loop. The whole bed volume including the connecting tubings was $83.8 \mathrm{ml}$, which was calculated from the difference in weight between empty and water-filled columns. The inlets of feed (the hydrolysate) and desorbent (distilled water) streams and the outlets of raffinate, extract, and effluent ones were joined between the columns. In this continuous chromatography, the less adsorptive peptide group I should be withdrawn exclusively into the raffinate stream, and the more adsorptive peptide group II in the extract one under proper operating conditions. The flow rates of feed, desorbent, raffinate, extract, and effluent streams were $0.104,1.753,0.698,0.391$, and $0.768 \mathrm{ml} / \mathrm{min}$, respectively. The inlets and outlets were periodically transported in the direction of liquid flow at 10 -min intervals. The details of operation were described in a previous paper. ${ }^{12)}$

To find whether the separation was successful, a conventional batch chromatography with Sephadex G-15 was done separately for the raffinate and extract, and their chromatograms were compared. The raffinate and extract solutions collected after the steady-state was established were lyophilized and then dissolved again with distilled water to give the concentration of about $5 \%(\mathrm{w} / \mathrm{v})$. The solutions ( $1 \mathrm{ml}$ each) were separately put on the resin bed of $1.45 \mathrm{~cm}$ i.d. $\times 45.1 \mathrm{~cm}$, and eluted with distilled water at the flow rate of $0.688 \mathrm{ml} / \mathrm{min}$.

Analysis of amino acid composition. The lyophilized samples were completely hydrolyzed with $6 \mathrm{~N} \mathrm{HCl}$ for $24 \mathrm{hr}$. The amino acid compositions were analyzed by an amino acid analyzer (Hitachi, L-8500). Tryptophan and tyrosin were measured spectrophotometrically. ${ }^{13)}$

\section{Results and Discussion}

Figure 1 shows the course of casein hydrolysis by the consecutive thermolysin and papain treatments. The liberation of free amino acids was not measured in this study, although

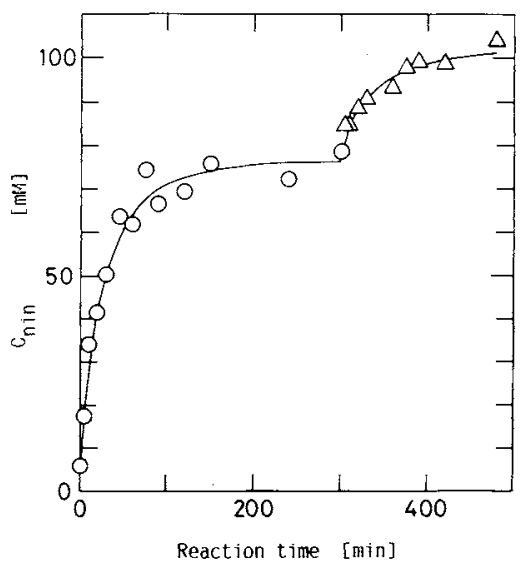

Fig. 1. Course of the Hydrolysis of Casein by Consecutive Thermolysin and Papain Treatments.

The casein concentration was $5 \%(\mathrm{w} / \mathrm{v})$. The hydrolysis was done using thermolysin $(O)$ and papin $(\triangle)$ consecutively. The ratio of enzyme to substrate was $1: 100$ in weight for both the enzymes. The $\mathrm{pH}$ was maintained at $7.5 \pm 0.1$ for thermolysin-catalyzed hydrolysis and at $6.5 \pm 0.1$ for the papain-catalyzed one. The ordinate, $C_{\text {nin }}$, indicates the concentration of ninhydrin-positive substances in the reaction mixture.

it might occur. If it is assumed that the coloration of the ninhydrin method is independent of the degree of polymerization of peptide and reflects the amount of aminoterminals, and that the mean molecular weight of an amino acid residue is 100 , the final conversion of casein is about $20 \%$, which may roughly indicate that the peptides produced are composed of five amino acid residues on an average. Since thermolysin tends to hydrolyze the peptide bonds of the amino-terminal sides of BCAA and AAA, ${ }^{14,15)}$ the peptides produced may be prone to have BCAA or AAA at their amino-terminals although further hydrolysis by papain has been done.

Since AAA and BCAA are hydrophobic, ${ }^{16)}$ we tried to separate the peptides rich in them through the hydrophobic interaction between peptides and gel chromatographic resin. Gel chromatographic resins generally have hydrophobic properties, ${ }^{7,9)}$ though they are weak. The hydrophobicity of each resin was estimated by measuring the elution volume of $n$-alcohols. Figure 2 shows the relationships between elution volume and molecular weight of 
$n$-alcohol. Toyopeal HW-40S, a polyvinyl resin, has the strongest hydrophobicity among the resins tested. Other resins have similar

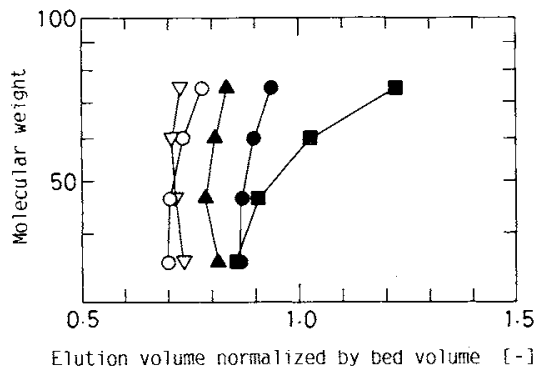

Fig. 2. Relationships between the Elution Volume and the Molecular Weight of $n$-Alcohol for some Gel Chromatographic Resins.

The resins used were Toyopearl HW-40S (ם), Sephadex G-15 (C), and Bio-Gel P-2 (A). The results presented by open symbols, $\nabla$ (Cellulofine GC-15m) and $\bigcirc$ (Sephadex G-10), were cited from the literature.9)

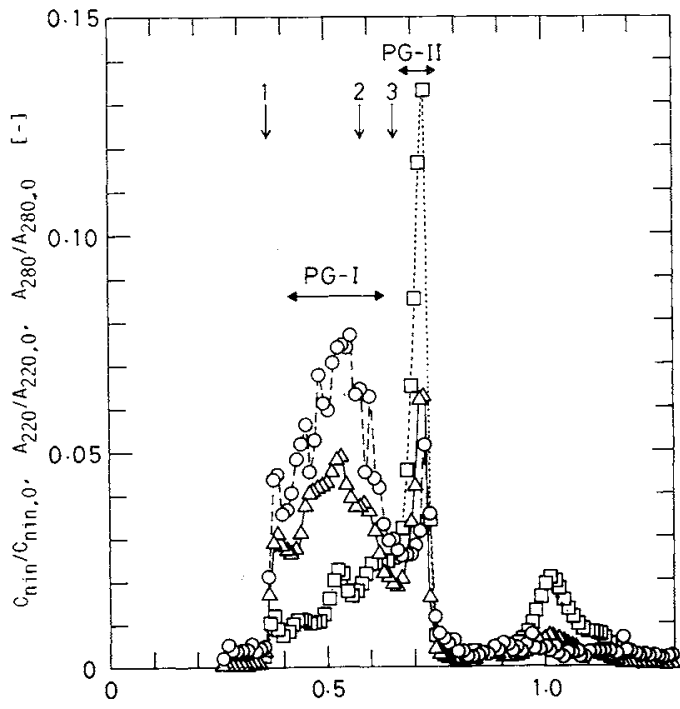

Elution volume normalized by bed volume $[-]$

Fig. 3. Elution Profiles of the Casein Hydrolysate in a Conventional Batch Chromatography with Sephadex G-15.

The hydrolysate $(15 \mathrm{ml})$ was put on the bed of $5.1 \mathrm{~cm}$ i.d. $\times 48.8 \mathrm{~cm}$, and then eluted with distilled water at the flow rate of $3.47 \mathrm{ml} / \mathrm{min} . A_{220}$ and $A_{280}$ in the ordinate represent the absorbances at $220 \mathrm{~nm}(\triangle-)$ and $280 \mathrm{~nm}(--\square---)$, respectively. $C_{\text {nin }}\left(--\mathrm{O}^{-}\right)$is the same as in Fig. 1 . The subscript 0 represents the feed. PG-I and PG-II indicate the peptide groups I and II, respectively. The arrows with the numbers 1,2 , and 3 , show the elution positions of bovine serum albumin, glycylglycylglycine, and glycine, respectively. relationships. A combination of a more hydrophobic solute and a more hydrophobic resin may largely retard the elution of a solute with a broad peak. This may indicate that the solute is greatly diluted and the productivity is decreased. Therefore, the resins with weaker hydrophobicities may be recommended for more hydrophobic solutes. On the other hand, the more hydrophobic resins are preferable for solutes with weaker hydrophobicity.

Since AAA is the strongest in hydrophobicity of amino acids, Sephadex G-15 was used to separate the AAA-rich peptides from the casein hydrolysate by an isocratic operation. Figure 3 illustrates the chromatogram. The chroma-

Table I. Amino Acid Compositions of the Casein Hydrolysate and the Peptide Groups I and II Prepared by Batch and Continuous Chromatographies ${ }^{a}$

\begin{tabular}{|c|c|c|c|c|c|}
\hline & \multirow{2}{*}{ Hydrolysate } & \multicolumn{2}{|c|}{ Batch } & \multicolumn{2}{|c|}{ Continuous } \\
\hline & & PG-I & PG-II & PG-I & PG-II \\
\hline Asx & 6.2 & 6.9 & 1.6 & 7.5 & 3.0 \\
\hline Thr & 4.4 & 5.0 & 1.2 & 4.9 & 2.7 \\
\hline Ser & 6.5 & 5.5 & 3.2 & 7.3 & 4.1 \\
\hline Glx & 18.5 & 18.4 & 10.1 & 21.5 & 11.4 \\
\hline Gly & 3.3 & 3.2 & 4.8 & 2.7 & 4.0 \\
\hline Ala & 4.3 & 4.2 & 4.3 & 4.2 & 4.5 \\
\hline Val & 7.0 & 7.6 & 4.9 & 6.9 & 6.0 \\
\hline Cys & 0.6 & 0.4 & 0.2 & 0.7 & 0.8 \\
\hline Met & 2.3 & 2.5 & 1.5 & 2.4 & 1.9 \\
\hline Ile & 4.6 & 4.7 & 2.2 & 4.7 & 3.3 \\
\hline Leu & 9.2 & 9.5 & 14.5 & 7.8 & 11.7 \\
\hline Tyr & 3.8 & 1.3 & 19.2 & 1.7 & 11.4 \\
\hline Phe & 4.2 & 3.0 & 15.8 & 2.7 & 9.3 \\
\hline Lys & 6.7 & 7.7 & 2.3 & 8.0 & 3.2 \\
\hline His & 2.2 & 2.5 & 1.1 & 1.8 & 3.1 \\
\hline Arg & 2.6 & 2.2 & 3.4 & 2.7 & 3.3 \\
\hline Pro & 12.6 & 15.2 & 6.4 & 12.3 & 14.3 \\
\hline $\operatorname{Trp}$ & 0.8 & 0.1 & 3.1 & 0.2 & 2.9 \\
\hline $\mathrm{BCAA}^{b}$ & 20.8 & 21.8 & 21.7 & 19.4 & 21.0 \\
\hline $\mathrm{AAA}^{c}$ & 8.8 & 4.4 & 38.1 & 4.6 & 23.6 \\
\hline Hydrophilic ${ }^{d}$ & 52.2 & 53.4 & 28.7 & 57.9 & 36.0 \\
\hline Fischer ratio $^{e}$ & 2.6 & 5.1 & 0.6 & 4.5 & 1.0 \\
\hline
\end{tabular}

a The contents are expressed by mol\%

$b$ Branched chain amino acids (Val + Leu + Ile)

c Aromatic amino acids (Tyr $+\mathrm{Phe}+\mathrm{Trp}$ ).

d Molar content of amino acids with a hydrophobic fragmental constant less than one

e Molar ratio of Val + Leu + Ile to Tyr + Phe. 
togram has three peaks. The third peak at the normalized elution volume of 1 may be ascribed to free tryptophan, judging from the elution pattern presented by Yamashita et al. with Sephadex G-15. ${ }^{7)}$ The first peak, PG-I in the figure, has low absorbance at $280 \mathrm{~nm}$. This peak was regarded as the AAA-poor peptide group I. The second peak, PG-II in the figure, with high absorbance at $280 \mathrm{~nm}$, was considered as the AAA-rich peptide group II. The peptide groups I and II obtained were $0.489 \mathrm{~g}$ $(61.4 \%)$ and $0.084 \mathrm{~g}(10.5 \%)$, respectively, from $0.799 \mathrm{~g}$ of the hydrolysate put on. The percentages in parentheses represent their recoveries.

The amino acid compositions of the peptide groups I and II were analyzed (Table I). The composition of the original hydrolysate is also presented. The AAA content of peptide group I was reduced to one-half that of the hydrolysate, and that of peptide group II was increased about 4-fold. BCAA was almost evenly divided into the groups. BCAA and AAA are metabolized in muscle and liver, respectively. In liver disease there occurs an imbalance of amino acids, especially the accumulation of AAA due to the metabolic disorder and the deficiency of BCAA due to its concomitant oxidative acceleration. The imbalance causes other diseases such as hepatic encephalopathy. Therefore, the Fischer ratio, which is defined as the molar ratio of $\mathrm{Val}+\mathrm{Leu}+\mathrm{Ile}$ to Phe + Tyr ${ }^{\left.1{ }^{1}\right)}$ is important in the therapy of patients with liver disease (cirrhosis). The reduction of AAA content in the peptide group I increased the ratio. The ratio of peptide group I was higher than that of peptide group II by a factor of about eight. Regarding the amino acids with a hydrophobic fragmental constant ${ }^{16)}$ less than one as hydrophilic ones, the summation of their contents was calculated and shown in the table as an indication of the expedient hydrophilicity of the peptides. An oral test also showed that peptide group I was less bitter than the hydrolysate. From these results, peptide group I may be useful as a nutritionally functional food or a food with improved properties.

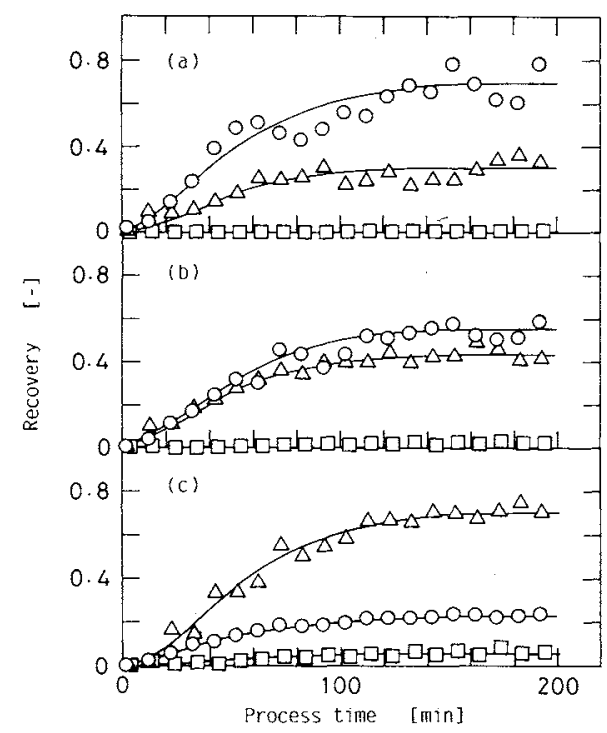

Fig. 4. Continuous Separation of Peptide Groups I and II from the Hydrolysate by the Chromatography of a Simulated Moving-bed Type.

The figures (a), (b), and (c) correspond to the nynhydrin-positive substances, absorbance at $220 \mathrm{~nm}$ and that at $280 \mathrm{~nm}$, respectively. The symbols $O, \triangle$, and $\square$ indicate the raffinate, extract, and effluent streams. The details of operating conditions are shown in the text.

As shown in Fig. 3, the peptide groups I and II have considerably different elution volumes. Therefore, their continuous separation was considered to be possible by using a chromatography of a simulated moving-bed type, and it was tried. Figure 4 shows the transient changes in the concentration of ninhydrin-positive substances and absorbances at 220 and $280 \mathrm{~nm}$ of the raffinate, extract, and effluent streams. About three-fourths of the dry materials included in the feed was recovered in the raffinate stream, and about one-fourth in the extract one. The recovery in the effluent stream was not measured because the amount was too small. Although the effluent stream is not necessary in the continuous chromatography where two pure components are separated, it was set up in this study because of operational ease and for another reason. In this separation system many components are included in the feed solution (the hydrolysate). If the operating conditions are set to elute the components of the third peak in the batch chromatography 


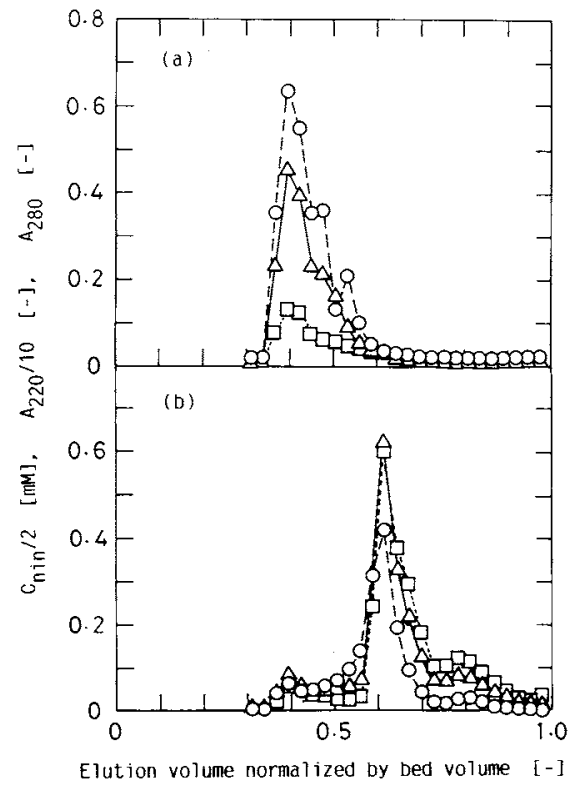

Fig. 5. Elution Profiles of the Raffinate and Extract in a Batch Chromatography with Sephadex G-15.

The raffinate and extract obtained by the continuous chromatography of a simulated moving-bed type were put through the batch chromatography. Figures (a) and (b) show the chromatograms for the raffinate and extract, respectively. The bed size was $1.45 \mathrm{~cm}$ i.d. $\times 45.1 \mathrm{~cm}$, and the eluent was distilled water. The concentrations of the raffinate and extract applied were both $5 \%(w / v)$. The symbols are the same as in Fig. 3.

into the extract stream, peptide group II, which should be exclusively withdrawn into the stream, is diluted and contaminated with the components of the third peak. Therefore, the operation in which the components of the third peak were partly recovered into the effluent stream was adopted.

In Fig. 4 it appears that the continuous separation of peptide groups I and II, although they are not strictly the same as those prepared in the batch chromatography, has been successful. To confirm this, the raffinate and extract obtained at the steady-state were separately put through the conventional batch chromatography with Sephadex G-15. Figures 5(a) and (b) illustrate the chromatograms for the raffinate and extract, respectively. These chromatograms demonstrate that the continuous separation was successful using the chromatography of the simulated moving-bed

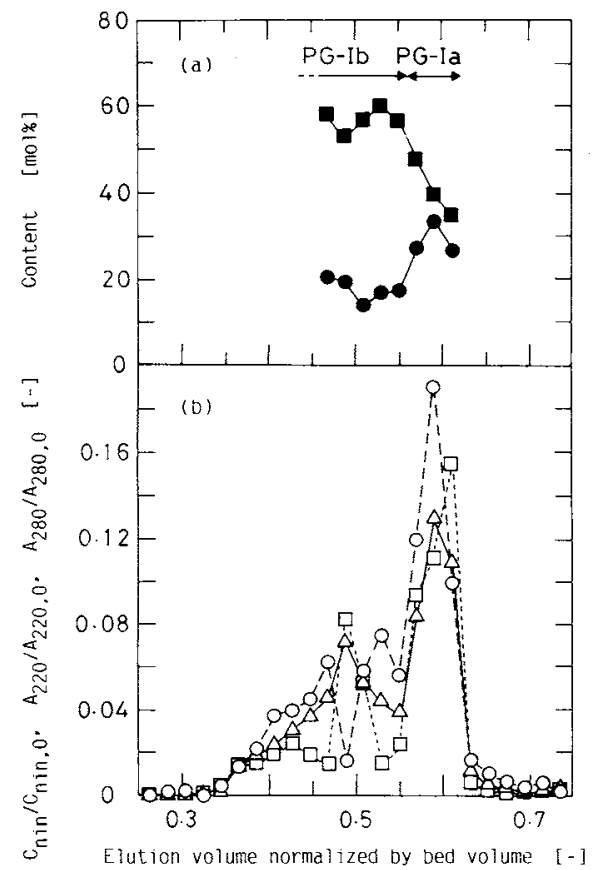

Fig. 6. Preparation of Peptide Groups Ia and $\mathrm{Ib}$ with High and Low Branched Chain Amino Acids from the Peptide Group I by the Conventional Batch Chromatography with Toyopearl HW-40S.

Two and a half $\mathrm{ml}$ of peptide group I solution of $5.0 \%$ $(\mathrm{w} / \mathrm{v})$ was put on. The bed dimension was $2.1 \mathrm{~cm}$ i.d. $\times 45.0 \mathrm{~cm}$. The eluent was distilled water. The open symbols, $O, \triangle$, and $\square$, in (b) are the same as in Fig. 3 . The closed symbols, and $\mathbf{Q}$, in (a) represent the contents of branched chain amino acids and hydrophilic ones, respectively.

type. The separation was also confirmed through the amino acid analyses of the raffinate and extract, which are shown in Table I. These results show that peptide group I with the low AAA content, higher Fischer ratio, and low bitterness can be prepared continuously.

Although the batch and continuous chromatographies with Sephadex G-15 made the separation of AAA-rich and -poor peptides possible, the enrichment of BCAA content was not. Accordingly, the further separation of peptide group I into two groups, BCAA-rich and -poor peptide groups, was tried with another resin. Since BCAA is weakly hydrophobic, a more hydrophobic resin than Sephadex G-15 was expected to retard the elution of BCAA-rich peptides more than 
hydrophilic ones. The separation of peptide group I was done by conventional batch chromatography with Toyopearl HW-40S, which had the strongest hydrophobicity among the resins tested (Fig. 6). Some fractions were analyzed for their amino acid compositions. The BCAA contents of the fractions are shown in the figure. The contents of hydrophilic amino acids with a hydrophobic fragmental constant less than one were also plotted. The content of hydrophilic amino acids was reduced as the elution volume became large, while the BCAA content increased in the latter fractions. The BCAA contents in the earlier and last three fractions were about 0.7 and 1.5 times as high as that of peptide group I. The fractions regarded as the peptide groups Ia and Ib are marked in the figure. This figure indicates that the enrichment of BCAA can be done by chromatography with strong hydrophobicity. However, the continuous separation of BCAArich and -poor peptide groups is thought to be difficult because their elution positions are very close.

As mentioned above, the preparation of four peptide groups with definite characteristics from the enzymatic casein hydrolysate were done by two steps of chromatographies with different resins. Although this study dealt only with a casein hydrolysate, the procedures described here may be applicable to other protein hydrolysates. The application of the procedures to other proteins is now in progress. When soybean protein isolate was used, similar results was obtained. The results will be presented elsewhere. In this study, the consecutive thermolysin and papain treatment was adopted from the viewpoints of the degree of hydrolysis and the hydrolytic site specificity of thermolysin. Since the hydrolysates by other proteinases were not put through the chromatographies, we cannot say whether they were successfully separated into some characteristic peptide groups or not. In this study, the peptide groups were separated by the weak hydrophobic interaction between peptides and chromatographic resin. The relation between the site specificity of proteinases used and the separation efficiency is interesting since the hydrophobicity of amino acids depends on their position in peptides. ${ }^{17)}$

The Fischer ratio of infusion solution for general purpose is between 3 and $6,{ }^{18)}$ and that of the solution for liver diseases is about $37 .^{1,18)}$ The ratio of the peptide group I prepared here was about 5 . Therefore, it is satisfactory for general purposes, but is not sufficient for liver diseases. There may be two ways to increase the ratio. One is an addition of free $\mathrm{BCAA}$ or BCAA-rich peptides, which are prepared chemically or enzymatically, to the peptide group I. Another is the development of a more efficient procedure to remove AAA-rich peptides from the hydrolysate. The latter is our goal, and further investigation on it will be done.

\section{References}

1) J. E. Fischer, H. M. Rosen, A. M. Ebeid, J. H. James, J. M. Keane and P. B. Soeters, Surgery, 80, 77 (1976).

2) Y. Muto, "Shoka Kyushu," Daiichi Shuppan, Tokyo, 1988, p. 234.

3) T. Matoba and T. Hata, Agric. Biol. Chem., 36, 1428 (1972).

4) J. F. Roland, D. L. Mattis, S. Kiang and W. L. Alm, J. Food Sci., 43, 1491 (1978).

5) K. Nakanishi, Y. Kimura and R. Matsuno, Eur. J. Biochem., 161, 541 (1986).

6) Y. Kimura, K. Nakanishi and R. Matsuno, Enzyme Microb. Technol., 12, 272 (1990).

7) M. Yamashita, S. Arai and M. Fujimaki, J. Food Sci., 41, 1029 (1976).

8) S. Takahashi, J. Biochem., 83, 57 (1978).

9) Y. Motozato, H. Ihara, M. Nakamura, M. Shiba and C. Hirayama, Nippon Kagaku Kaishi, 1988, 61.

10) D. B. Broughton, R. W. Nuezil, J. M. Pharis and C. S. Brearly, Chem. Eng. Prog., 66, 70 (1970).

I1) K. Hashimoto, S. Adachi, H. Noujima and H. Maruyama, J. Chem. Eng. Japan, 16, 400 (1983).

12) K. Hashimoto, S. Adachi and Y. Shirai, Agric. Biol. Chem., 52, 2161 (1988).

13) H. Edelhoch, Biochemistry, 7, 1948 (1967).

14) H. Matsubara, R. M. Sasaki, A. Singer and T. H. Jukes, Arch. Biochem. Biophys., 115, 324 (1966).

15) K. Morihara, Adv. Enzymol., 41, 179 (1974).

16) R. F. Rekker, "The Hydrophobic Fragmental Constant," Elsevier, 1977, p. 301.

17) M. Akamatsu, "Quantitative Analysis of Hydro- 
phobicity of Oligopeptides Using Physicochemical Amino Acid Side Chain Parameters and Submolecular Structural Descriptors," 1990, Chapter 3,
Doctoral Thesis of Kyoto Univ.

18) A. Okada, Kagaku To Seibutsu, 27, 585 (1989). 